\title{
PLANEJAMENTO TRIBUTÁRIO: COMPARATIVO ENTRE AS MODALIDADES SIMPLES NACIONAL E LUCRO PRESUMIDO
}

\section{ARTIGO ORIGINAL}

VIDAL, Aline Xavier Monteiro1, MARTINS, Maria Hortencia da Silva², AGDO, Jeferson Alves ${ }^{3}$, LAVOR JUNIOR, Alex de Lima ${ }^{4}$, MACIEL JÚNIOR, Alder Ronaldo da Silva ${ }^{5}$, ROBERTO, José Carlos Alves ${ }^{6}$, SERRA, Meg Rocha da Cunha ${ }^{7}$, LOPES, Nelânia Ferreira ${ }^{8}$

VIDAL, Aline Xavier Monteiro. Et al. Planejamento tributário: comparativo entre as modalidades simples nacional e lucro presumido. Revista Científica Multidisciplinar Núcleo do Conhecimento. Ano. 06, Ed. 11, Vol. 04, pp. 39-60. Novembro 2021. ISSN: 2448-0959, Link de acesso: https://www.nucleodoconhecimento.com.br/contabilidade/lucro-presumido, DOI: 10.32749/nucleodoconhecimento.com.br/contabilidade/lucro-presumido

\section{RESUMO}

Com o crescente número de empreendedores surgindo na sociedade, sejam eles de pequeno, médio ou grande porte, manter um bom planejamento tributário tornou-se primordial para garantir que as entidades possam manter suas obrigações frente ao fisco. Portanto, este artigo busca apresentar o que vem a ser o planejamento tributário e quais são os regimes tributários presentes na legislação brasileira, com enfoque no Simples Nacional e no Lucro Presumido, de modo a proporcionar uma

\footnotetext{
${ }^{1}$ Graduando do curso de Contabilidade.

${ }^{2}$ Graduando do curso de Contabilidade.

${ }^{3}$ Graduando do curso de contabilidade.

${ }^{4}$ Graduando do curso de Contabilidade.

${ }^{5}$ Graduando do curso de Contabilidade.

${ }^{6}$ Orientador. Mestre em Engenharia de produção. Especialista Logística empresarial. Graduado em Administração com Ênfase em Marketing.

${ }^{7}$ Orientadora. Mestra em Engenharia de Processos Industriais pela UFPA, especialista em Controladoria e Auditoria Contábil pelo Ciesa (2020), Graduada em Ciências Contábeis pelo Centro Universitário do Norte (2010). Graduada em Ciências Econômicas pelo Centro Universitário do Norte (2006).

${ }^{8}$ Orientadora. Especialista em Auditoria Contábil, Financeira e Tributaria e Graduada em Ciências Contábeis.
}

RC: 100779

Disponível em: https://www.nucleodoconhecimento.com.br/contabilidade/lucropresumido 
melhor eficiência na redução dos impostos, levando a melhores resultados econômico-financeiros às empresas. Parte-se, principalmente, da grande falta de informação dispostas às pessoas que não possuem contato com termos e procedimentos contábeis e, devido à ausência de tais informações, grande é o número de erros que ocorrem ao decidir o regime de tributação, que leva a inadimplência junto ao fisco bem como multas e perdas financeiras. Assim, sendo, tem como questão norteadora: Qual a importância de um planejamento tributário para as empresas, independente do porte, ramo de atividade ou forma de tributação? O objetivo geral do presente estudo será detalhar cada Regime Tributário e identificar como eles irão contribuir para a redução de tributação. 0 desenvolvimento deste artigo foi baseado em pesquisas bibliográficas em livros e legislações, onde apresentam-se todos impostos e percentuais dos regimes tributários apresentados, para cada tipo de ramo empresarial sejam eles comércios, serviços ou indústrias, seu porte e sua renda obtida. Com base nos dados apresentados, pode-se avaliar a situação da empresa na sua fundação e garantir que a mesma obtenha bons resultados, fazendo o uso do planejamento tributário no futuro para que seja avaliada uma mudança de regime tributário dependendo da expansão da empresa.

Palavras-chave: Planejamento tributário, Impostos, Regime tributário.

\section{INTRODUÇÃO}

O planejamento tributário tornou-se imprescindível para as empresas e uma estratégia essencial para o andamento do negócio. Devido à alta carga tributária no Brasil e da complexidade da legislação brasileira, requer-se estudos prévios da atividade econômica com base na legislação, verificando possíveis restrições quanto a aplicação prática da tributação escolhida e realizando simulações dos valores devidos ao fisco em cada regime tributário por meio da elaboração de um planejamento tributário eficiente. 
O objetivo geral do presente estudo será detalhar cada Regime Tributário e identificar como eles irão contribuir para a redução de tributação. Assim, os objetivos específicos serão: Conceituar o Planejamento tributário, o Regime do Simples Nacional e o Lucro Presumido; Analisar a escolha do regime tributário por parte da empresa; e, por último, será feita uma comparação dos cálculos e uma análise da forma mais econômica de tributação para a empresa.

Em paralelo a isso, o tema abordado busca sanar uma deficiência social que surge da falta de conhecimento contábil por parte do empresário em potencial que, ao dar início às atividades da sua empresa, pode aderir a um regime tributário que não condiz com a capacidade lucrativa da empresa, levando o mesmo a pagar tributos exorbitantes, de modo a diminuir a sua margem de lucro.

Problema é uma questão inerente a uma complexidade teórica ou prática para a qual deve ser encontrada uma resolução (ROVIGATI, 2009). Sendo assim, esse trabalho busca responder à pergunta problema que auxilia a pesquisa: Qual a importância de um planejamento tributário pelas empresas, independente do porte, ramo de atividade ou forma de tributação?

A metodologia foi constituída por métodos bibliográficos, através de livros das áreas do direito tributário e da contabilidade, e de artigos científicos que possibilitam esclarecer todos os objetivos do tema abordado.

\section{FUNDAMENTAÇÃO TEÓRICA}

Este tópico compreende o referencial teórico da pesquisa, onde estão expostos os conceitos e dados relacionados ao tema, discutindo-os conforme o intuito do trabalho. Os autores consultados e conceitos apresentados estão apresentados sequencialmente, com suas referências evidenciadas (LIBÓRIO e TERRA, 2015).

RC: 100779

Disponível em: https://www.nucleodoconhecimento.com.br/contabilidade/lucropresumido 


\subsection{PLANEJAMENTO TRIBUTÁRIO}

O planejamento tributário é de suma importância para as organizações e uma estratégia essencial para o andamento do negócio, devido a nossa elevada carga tributária, representando grande impacto na vida das empresas.

"Em sentido comum, a expressão "planejamento tributário" é utilizada para fazer referência a uma atividade ou técnica de prospecção de alternativas de redução da carga tributária suportada pelas pessoas e pelas empresas, sempre em consonância com o ordenamento jurídico em vigor" (ANDRADE, 2015).

Por esse motivo, é muito importante conhecer quais são as formas legais para fazer um bom planejamento tributário, que ajude na redução de tributos, verificando possíveis restrições quanto a aplicação prática da tributação escolhida, a fim de mantê-la ativa no mercado.

"Vale lembrar que um planejamento tributário indevidamente elaborado pode gerar uma evasão fiscal, em vez da elisão fiscal. A evasão também reduz a carga tributária, mas por meios ilegais e é classificada como crime de sonegação fiscal" (CREPALDI, 2012).

Posto isso, busca-se em primeira análise conhecer a empresa através de suas práticas contábeis e gerenciais, além da sua área de atuação e, em conformidade com as leis vigentes, estabelecer possibilidades de economia tributária.

Isso tudo antes de ocorrer o fato gerador, pois se ocorrer antes não será possível realizar o planejamento tributário. Se ocorrer depois do fato gerador, torna-se uma ação criminosa, sonegação fiscal, ficando à mercê de penalidades da lei.

\subsubsection{TIPOS DE PLANEJAMENTO TRIBUTÁRIO}

São três os planejamentos existentes: planejamento operacional, planejamento estratégico e o planejamento operacional. 
Planejamento operacional é aquele que se utiliza no dia a dia da organização e é de curto prazo, visando que as metas planejadas sejam cumpridas dentro do prazo estabelecido, acompanhando e prevenindo erros de envio das obrigações para os órgãos fiscalizadores.

Tal planejamento é de responsabilidade dos colaboradores, onde são responsáveis pela execução das tarefas. Desta forma, os objetivos do nível operacional são de curto prazo, focado nas operações rotineiras da empresa (ANDRADE, 2012, p. 13).

Planejamento Estratégico, geralmente usado no período a longo prazo, é utilizado para mapear e implementar a melhor estratégia para alcançar os objetivos propostos e monitorar os resultados.

Oliveira (2010, p. 17-18) diz que Planejamento estratégico é o processo administrativo que proporciona sustentação metodológica para se estabelecer a melhor direção a ser seguida pela empresa. Ele tem um objetivo a ser alcançado através de ações em um longo prazo.

Planejamento Tático é aquele que envolve todas as áreas da empresa, em um período de médio prazo, é como se estivesse entre o planejamento operacional e o planejamento estratégico.

O Planejamento Tático é de responsabilidade dos gestores que são responsáveis pelas decisões que afetam cada departamento da empresa. Nele são definidos os objetivos de médio prazo podendo ser o exercício fiscal ou anual da empresa (ANDRADE, 2012, p. 13).

\subsection{REGIME TRIBUTÁRIO}

Tributos são prestações pecuniárias compulsórias, conforme estabelece 0 artigo $3^{\circ}$ do Código Tributário Nacional (CTN). "Logo, tributos são um gênero, que possui diversos tipos, cujos quais estão previstos em lei como impostos, taxas e contribuições.

RC: 100779

Disponível em: https://www.nucleodoconhecimento.com.br/contabilidade/lucropresumido 
Enquanto, o Regime Tributário é o sistema que determina a forma como a cobrança de impostos será realizada em cada empresa, determinado de acordo com o montante arrecadado pela entidade e pela atividade executada pela mesma, seja ela de comércio, serviços ou indústria. Determinar o regime tributário direciona a tratativa para com o fisco e garante o cumprimento das obrigações, tais como o pagamento dos tributos e o SPED Fiscal. No Brasil, existem três tipos principais de Regimes Tributários, cujos quais, dois deles são o enfoque do projeto aqui apresentado, o Simples Nacional e o Lucro Presumido.

\subsubsection{SIMPLES NACIONAL}

O Simples Nacional trata-se de um regime tributário diferenciado, simplificado e favorecido, regulado pela Lei Complementar no 123, de 14.12.2006, com modificações trazidas por leis posteriores, aplicável às microempresas e às empresas de pequeno porte, a partir de 01.07.2007.

De acordo com Santiago (2011, p. 148), o Simples Nacional é uma alternativa de tributação, cujas microempresas e empresas de pequeno porte podem escolher como forma de pagamento de tributos.

Este sistema abrange todos os entes da Federação e é facultativo, mas irretratável para o ano calendário. O recolhimento é mensal, através de um documento único de arrecadação a ser pago até o último dia da primeira quinzena ao mês subsequente em que a receita tiver sido auferida.

De acordo com Naylor (2009, p. 3), o Simples Nacional não é um novo tributo, visto que não gerou nenhuma nova obrigação tributária principal, além daqueles já existentes, relativa aos impostos e contribuições que foram incluídos no novo regime.

Segundo Naylor (2009, p. 4), a finalidade do Simples nacional é tornar eficazes os princípios constitucionais aplicáveis às microempresas e empresas de pequeno porte [...]. Comportando-se como um subsistema tributário especial, que assume um

RC: 100779

Disponível em: https://www.nucleodoconhecimento.com.br/contabilidade/lucropresumido 
caráter parcialmente substitutivo ao sistema geral, o novo regime afasta ou limita parcialmente a eficácia de alguns princípios para tornar-se realmente efetivos outros, aplicáveis às microempresas e empresas de pequeno porte.

Para enquadrar-se no Simples Nacional, a empresa não pode ter faturamento anual maior que $R \$ 4,8$ milhões, caso ultrapasse esse valor não poderá ser optante pelo Simples Nacional. A vantagem de optar pelo simples ajuda a reduzir a carga tributária e unificar o pagamento em um tributo único.

\subsubsection{TIPOS DE TRIBUTOS}

Os tipos de tributos presentes no Simples Nacional são compostos pela soma de todos os impostos Estaduais e Federais das empresas prestadoras de serviço, sendo eles: IRPJ, CSLL, COFINS, PIS, INSS e o ICMS.

O Art.77 do Código Tribunal Nacional e o Art.145 da Constituição da república federativa do Brasil de 1988 descrevem a Taxa como: "Um tributo imediatamente vinculado à ação estatal específica relativa ao contribuinte, cujo fato gerador é o exercício regular do poder de polícia, ao serviço público prestado ao posto à disposição do contribuinte".

De acordo com o Art.145 da Constituição Federal,

A União, os Estados, e o Distrito Federal e os Municípios poderão instituir os seguintes tributos:

I - Impostos;

II - Taxas, em razão do exercício do poder de polícia ou pela utilização, efetiva ou potencial, de serviços públicos específicos e divisíveis, prestados ao contribuinte ou postos a sua disposição;

III- contribuição de melhoria, decorrente de obras públicas.

O Art. 16 do CTN descreve que "Imposto é o tributo cuja obrigação tem por fato gerador, uma situação independente de qualquer atividade estatal específica, relativa ao contribuinte"

RC: 100779

Disponível em: https://www.nucleodoconhecimento.com.br/contabilidade/lucropresumido 
Tabela 1 - Anexo III - Prestadores de Serviços

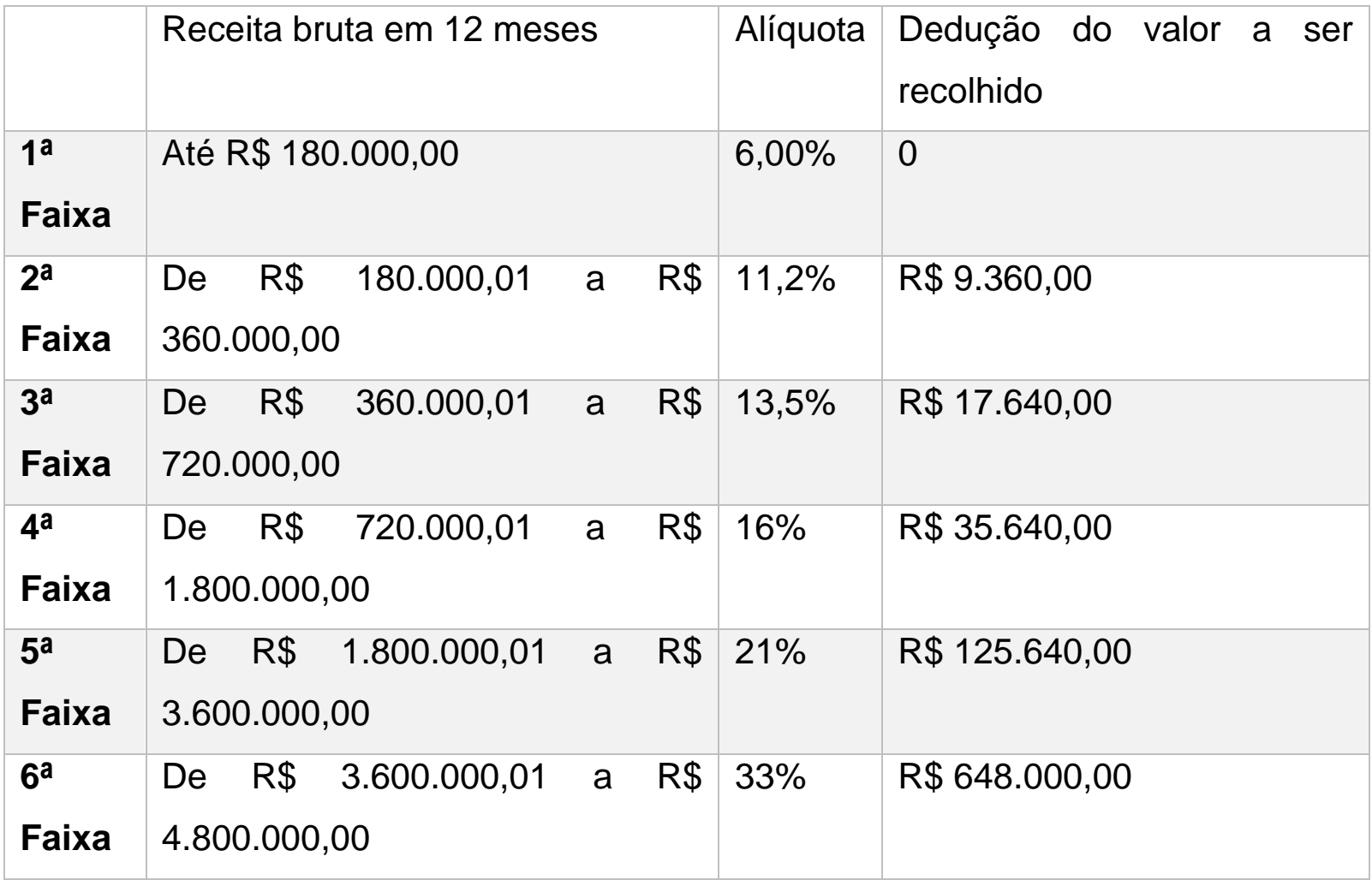

Fonte: Site da Receita Federal do Brasil

Tabela 2 - Percentual de Repartições de Tributos

\begin{tabular}{|l|l|l|l|l|l|}
\hline IRPJ & CSLL & COFINS & Pis & CPP & ISS \\
\hline $\mathbf{4 , 0 0} \%$ & $3,50 \%$ & $12,82 \%$ & $2,78 \%$ & $43,40 \%$ & $33,50 \%$ \\
\hline $\mathbf{4 , 0 0} \%$ & $3,50 \%$ & $14,05 \%$ & $3,05 \%$ & $43,40 \%$ & $32,00 \%$ \\
\hline $\mathbf{4 , 0 0} \%$ & $3,50 \%$ & $13,64 \%$ & $2,96 \%$ & $43,40 \%$ & $32,50 \%$ \\
\hline $\mathbf{4 , 0 0} \%$ & $3,50 \%$ & $13,64 \%$ & $2,96 \%$ & $43,40 \%$ & $32,50 \%$ \\
\hline $\mathbf{4 , 0 0} \%$ & $3,50 \%$ & $12,82 \%$ & $2,78 \%$ & $43,40 \%$ & $33,50 \%$ \\
\hline $\mathbf{3 5 , 0 0} \%$ & $15,00 \%$ & $16,03 \%$ & 3,74 & $43,40 \%$ & - \\
\hline
\end{tabular}

Fonte: Site da Receita Federal do Brasil

RC: 100779

Disponível em: https://www.nucleodoconhecimento.com.br/contabilidade/lucropresumido 
O Simples Nacional caracteriza-se por ser um regime tributário simples e diferenciado que surgiu especificamente para microempresas e empresas de pequeno porte.

\subsubsection{LUCRO PRESUMIDO}

O Lucro Presumido é uma modalidade de apuração facilitada do Imposto de Renda (IR) e da Contribuição Social sobre o Lucro Líquido (CSLL). Limita-se aos contribuintes que não estão constritos pelo regime de apuração do Lucro Real. As empresas que optarem pelo Lucro Presumido, não possuirão a obrigação da escrituração contábil acurada de suas receitas. Outrora, as despesas necessitam unicamente da escrituração do livro caixa, porque é compulsório no Lucro Real, ressaltando que este livro necessita ser escriturado dentro das normas e dos princípios da legislação fiscal vigente (OLIVEIRA et al., 2013, p. 199).

Segundo Fabretti (2009, p. 219), "o Lucro Presumido tem a finalidade de simplificar o pagamento do Imposto de Renda, é uma alternativa para as empresas de menor porte, até o limite da receita bruta total estabelecido em lei. Em vez de ser apurada pelo Lucro Real, poderão presumir esse lucro na escrituração contábil”.

Para enquadrar-se no lucro presumido, as empresas não podem constar na obrigação de optar pelo lucro real. Após concluir a opção pela tributação do Lucro Presumido, ela terá duração de todo ano-calendário, não sendo factível a pessoa jurídica mudar a forma de tributação.

\subsubsection{EMPRESAS AUTORIZADAS PELA TRIBUTAÇÃO DO LUCRO PRESUMIDO}

A Lei 9.718 de dezembro de 1998 define em seu Art. 13ำ que as pessoas jurídicas que poderão optar pelo Lucro Presumido, são:

Art. 13. A pessoa jurídica cuja receita bruta total no ano calendário anterior tenha sido igual ou inferior a $\mathrm{R} \$ 78.000 .000,00$ (setenta e oito milhões de

RC: 100779

Disponível em: https://www.nucleodoconhecimento.com.br/contabilidade/lucropresumido 
reais) ou a $R \$$ : $6.500 .000,00$ (seis milhões e quinhentos mil reais) multiplicado pelo número de meses de atividade do ano-calendário anterior, quando inferior a 12 (doze) meses, poderá optar pelo regime de tributação com base no lucro presumido.

$\S 1^{\circ}$ A opção pela tributação com base no lucro presumido será definitiva em relação a todo o ano-calendário.

$\S 2^{\circ}$ Relativamente aos limites estabelecidos neste artigo, a receita bruta auferida no ano anterior será considerada segundo o regime de competência ou de caixa, observado o critério adotado pela pessoa jurídica, caso tenha, naquele ano, optado pela tributação com base no lucro presumido.

Segundo Higuchi (2014, p. 58), as empresas que optarem pelo regime do Lucro Presumido devem possuir receita total, no período de apuração, não superior a $R \$$ 78.000.000,00. Qualquer empresa que não estiver enquadrada nas obrigatoriedades do Lucro Real pode aderir ao regime do Lucro Presumido.

\subsubsection{APURAÇÃO E OPÇÃO DO LUCRO PRESUMIDO}

O Lucro Presumido poderá ser apurado de duas formas: trimestral (a base de cálculo será a receita bruta) ou mensal (uma vez que nesta forma de apuração o contribuinte deverá recolher um DARF com o código 2089). É importante salientar que, se a empresa optar pela apuração mensal, deve-se ter muito cuidado para que nesse intervalo sejam ajustados os valores pelo efetivamente devido no último mês trimestral (BALBINOT, 2014, p. 38; OLIVEIRA et al., 2013, p. 200).

Oliveira et al. (2013, p. 200) evidencia que a opção pelo Lucro Presumido pode ser feita por empresas dos ramos industriais, comerciais e prestadoras de serviços que, no ano calendário anterior, possuíram uma receita bruta menor que $R \$$ 78.000.000,00, mas se a pessoa jurídica iniciou suas atividades no decorrer do ano o limite passa a ser $R \$ 4.000 .000,00$.

As alíquotas no regime do Lucro Presumido são regidas pela Receita Federal a partir de uma norma específica. Nesse regime, são apurados apenas o Imposto de Renda de Pessoa Jurídica (IRPJ) e Contribuição Social sobre o Lucro Líquido 
(CSLL). As alíquotas para o pagamento desses impostos são baseadas em uma presunção de lucro. Desta forma, os valores a serem pagos, nesse caso, são:

- $15 \%$ para faturamento que não ultrapasse o valor de $R \$ 187.500,00$ trimestral;

- $25 \%$ para faturamento trimestral superior a $\mathrm{R} \$ 187.500,00$;

- Adicional de $10 \%$ aplicável sobre a parcela do lucro presumido que exceder o limite de $R \$ 60.000,00$ no trimestre, ou $R \$ 20.000,00$ de Contribuição Social sobre o Lucro Líquido;

- $9 \%$ sobre o valor do faturamento trimestral.

\subsubsection{TIPOS DE TRIBUTOS}

Os tipos de tributos presentes no Lucro Presumido são basicamente: Imposto de Renda Pessoa Jurídica (IRPJ), Contribuição Social Sobre o Lucro Líquido (CSLL), Programa de Integração Social (PIS) e Contribuição para o financiamento da Seguridade Social (COFINS).

\subsection{IMPOSTO DE RENDA PESSOA JURÍDICA (IRPJ)}

Tabela 3: Percentual de presunção do lucro sobre receita bruta

\begin{tabular}{|l|l|l|l|}
\hline ATIVIDADES & Receita Bruta & Alíquota & $\begin{array}{l}\text { Lucro } \\
\text { Presumido }\end{array}$ \\
\hline Indústria e comércio em geral & $\begin{array}{l}\mathrm{R} \$ \\
1.000 .000,00\end{array}$ & $8 \%$ & $\mathrm{R} \$ 80.000,00$ \\
\hline Serviços em geral & $\mathrm{R} \$$ & $32 \%$ & $\mathrm{R} \$ 320.000,00$ \\
\hline Transporte de cargas & $1.000 .000,00$ & & \\
\hline Serviço hospitalares & $\mathrm{R} \$$ & $8 \%$ & $\mathrm{R} \$ 80.000,00$ \\
\hline & $1.000 .000,00$ & & \\
\hline & $\mathrm{R} \$$ & $8 \%$ & $\mathrm{R} \$ 80.000,00$ \\
\hline
\end{tabular}

RC: 100779

Disponível em: https://www.nucleodoconhecimento.com.br/contabilidade/lucropresumido 


\begin{tabular}{|c|c|c|c|}
\hline $\begin{array}{l}\text { Serviços de Transporte } \\
\text { (exceto de cargas) }\end{array}$ & $\begin{array}{l}\mathrm{R} \$ \\
1.000 .000,00\end{array}$ & $16 \%$ & $\mathrm{R} \$ 160.000,00$ \\
\hline $\begin{array}{l}\text { Revenda de combustível para } \\
\text { consumo }\end{array}$ & $\begin{array}{l}\mathrm{R} \$ \\
1.000 .000,00\end{array}$ & $1,6 \%$ & $\mathrm{R} \$ 16.000,00$ \\
\hline
\end{tabular}

Fonte: Manual da Contabilidade Tributária (OLIVEIRA et al., 2013, p.202)

É regulamentado pela Lei №8451, de 23 de dezembro de 1992, a partir do Art. $13^{\circ}$. As Pessoas Jurídicas tributadas pelo Lucro Presumido têm como objetivo principal o lucro, visto que elas devem presumi-lo no final de cada trimestre. A Legislação vigente fixou os percentuais que incidem sobre o valor total das vendas, a presunção do imposto é feita com base nesses percentuais fixados.

Concordante com Oliveira et al. (2013, p. 202), as Pessoas Jurídicas que realizam atividades relacionadas à prestação de serviços, exceto hospitalares e transportes, que arrecadam receita bruta de até $\mathrm{R} \$ 120.000,00$ anualmente, utilizarão o percentual de $16 \%$ sobre o faturamento mensal conforme a tabela acima.

Para realizar o cálculo do Imposto de Renda, o valor da receita deverá ser multiplicado pelo percentual de presunção e, em seguida, a alíquota de $15 \%$ deverá ser aplicada sobre os ganhos de capital e outras receitas, tais como: locação de imóveis, descontos obtidos, Juros recebidos, entre outras. Caso o faturamento trimestral ultrapasse o valor de $\mathrm{R} \$ 60.000,00$, estará sujeita à incidência da alíquota adicional de Imposto de Renda de 10\% sobre o valor excedente (OLIVEIRA, et al., 2013).

O vencimento do Documento de Arrecadação de Receitas Federais (DARF) do Imposto de Renda é no último dia do mês subsequente da apuração, uma vez que os prazos de recolhimento são trimestrais. 


\subsection{CONTRIBUIÇÃO SOCIAL SOBRE O LUCRO LÍQUIDO (CSLL)}

É regulamentado pela Lei $N^{\circ} 7689$, de 15 de dezembro de 1988, a partir do Art. $1^{\circ}$. No regime de tributação do Lucro presumido, a forma de apurar a CSLL é a mesma do Imposto de Renda, portanto, a base de cálculo da CSLL diz respeito ao valor das receitas ao final do trimestre, onde a alíquota fixada pela Lei é de $12 \%$.

O resultado da operação deverá ser somado com o valor de aplicações financeiras de renda fixa e os ganhos de capital, porque estes não são parte do objeto da Pessoa Jurídica, se o resultado for positivo, será acrescentado no Lucro Presumido e tributados em 9\% (BARTH, 2014, p. 50-51).

Rodrigues et al. (2013), ao mencionar a Lei $\mathrm{n}^{\circ}$ 9.249, destaca as atividades em que são aplicadas o percentual de presunção de $32 \%$ :

a) prestação de serviços em geral, exceto a de serviços hospitalares e de transportes, inclusive de cargas;

b) intermediação de negócios;

c) administração, locação ou cessão de bens imóveis, móveis e direitos de qualquer natureza;

d) prestação cumulativa e contínua de serviços de assessoria creditícia, mercadológica, gestão de crédito, seleção de riscos, administração de contas a pagar e a receber, compra de direitos creditórios resultantes de vendas mercantis a prazo ou de prestação de serviços (factoring) (RODRIGUES et al., 2013, p.343).

Tabela 4: Percentual de presunção do lucro sobre receita bruta

\begin{tabular}{|l|l|l|l|}
\hline Atividades & Receita Bruta & CSLL & Presumido \\
\hline Indústria e comércio em geral & $R \$$ & $12 \%$ & $R \$$ \\
\hline Serviços em geral & $1.000 .000,00$ & & $120.000,00$ \\
\hline & $R \$$ & $32 \%$ & $R \$$ \\
\hline & $1.000 .000,00$ & & $320.000,00$ \\
\hline
\end{tabular}

RC: 100779

Disponível em: https://www.nucleodoconhecimento.com.br/contabilidade/lucropresumido 


\begin{tabular}{|c|c|c|c|}
\hline Transporte de cargas & $\begin{array}{l}\mathrm{R} \$ \\
1.000 .000,00\end{array}$ & $32 \%$ & $\begin{array}{l}\mathrm{R} \$ \\
320.000,00\end{array}$ \\
\hline Serviço hospitalares & $\begin{array}{l}\mathrm{R} \$ \\
1.000 .000,00\end{array}$ & $12 \%$ & $\begin{array}{l}\mathrm{R} \$ \\
120.000,00\end{array}$ \\
\hline $\begin{array}{l}\text { Serviços de Transporte } \\
\text { (exceto de cargas) }\end{array}$ & $\begin{array}{l}\mathrm{R} \$ \\
1.000 .000,00\end{array}$ & $12 \%$ & $\begin{array}{l}R \$ \\
120.000,00\end{array}$ \\
\hline $\begin{array}{l}\text { Revenda de combustível para } \\
\text { consumo }\end{array}$ & $\begin{array}{l}\mathrm{R} \$ \\
1.000 .000,00\end{array}$ & $12 \%$ & $\begin{array}{l}R \$ \\
120.000,00\end{array}$ \\
\hline
\end{tabular}

Fonte: Manual da Contabilidade Tributária, Oliveira et al (2013, p.202)

Segundo Rodrigues et al. (2013), a base de cálculo da CSLL devida às pessoas jurídicas optantes pelo lucro presumido corresponde a:

- $12 \%$ da receita bruta nas atividades industriais, comerciais, serviços de transporte e hospitalares;

- 32 \% para: a) Prestação de serviços em geral, exceto a de serviços hospitalares e Transportes; b) Intermediação de negócios; c) Administração, locação ou cessão de bens imóveis, móveis e direitos de qualquer natureza.

O vencimento do Documento de Arrecadação de Receitas Federais (DARF) do CSLL ocorre no último dia do mês subsequente da apuração, uma vez que os prazos de recolhimento são trimestrais.

\subsection{PROGRAMA DE INTEGRAÇÃO SOCIAL (PIS)}

É regulamentada pela Lei Complementar № 7, de 7 de setembro de 1970, a partir do Art. $1^{\circ}$ e a Lei 9.715 , de 25 de novembro de 1998 , que tem como finalidade financiar a Seguridade Social.

A Lei 9.715 , de 25 de novembro de 1998 , no seu art. $2^{\circ}$, determina que "a contribuição do PIS será apurada mensalmente pelas pessoas jurídicas de direito

RC: 100779

Disponível em: https://www.nucleodoconhecimento.com.br/contabilidade/lucropresumido 
privado e as que lhes são equiparadas pela legislação do imposto de renda, inclusive as empresas públicas e as sociedades de economia mista com base no faturamento do mês".

Para Pinto (2011, p. 24), a apuração do PIS é executada mensalmente sobre o faturamento, aplicando-se uma alíquota de 0,65\%, para as pessoas jurídicas. As pessoas jurídicas imunes do PIS possuem a garantia assegurada de sua imunidade pela Constituição Federal, especificamente no Art. 150. As entidades imunes mais comuns no meio social em que vivemos são: Os templos e igrejas; Partidos políticos; Fundações e Sindicatos de trabalhadores.

A incidência cumulativa vale para as empresas que são tributadas pelo lucro presumido. A alíquota é $0,65 \%$ do PIS, sendo assim, o cálculo ocorre da seguinte maneira: PIS = receita bruta + soma da alíquota $(+0,65 \%)$.

\section{Exemplo: Receita Bruta: $\mathrm{R} \$ 1.000 .000,00 \times 0,65 \%=\mathrm{R} \$ 6.500,00$}

O vencimento do Documento de Arrecadação de Receitas Federais (DARF) do PIS é no dia 25 do mês seguinte ao da apuração, uma vez que é cobrado de forma cumulativa. Desta forma, não é possível a recuperação do PIS (não se utiliza créditos).

\subsection{CONTRIBUIÇÃO PARA O FINANCIAMENTO DA SEGURIDADE SOCIAL (COFINS)}

A Contribuição para Financiamento da Seguridade Social (COFINS) é regulamentada pela Lei Complementar $\mathrm{N}^{\circ} 70$, de 30 de dezembro de 1991 e Lei $\mathrm{N}^{\circ}$ 9718, de 27 de novembro de 1998.

É interessante ressaltar que o cálculo da COFINS na apuração pelo Lucro Presumido é semelhante à apuração do Lucro Real, porque é um tributo que também incide sobre a Receita Bruta das pessoas jurídicas, sendo apurado mensalmente. A data limite para recolhimento da DARF da COFINS é no dia 25 do

RC: 100779

Disponível em: https://www.nucleodoconhecimento.com.br/contabilidade/lucropresumido 
mês seguinte ao da apuração, cuja alíquota a ser aplicada é de $3 \%$ sobre o faturamento. Vale lembrar que, assim como o PIS, não é possível tomar crédito do imposto, uma vez que ele é cumulativo (PINTO, 2011, p. 24-25).

\section{Exemplo: Receita Bruta: $\mathrm{R} \$ 1.000 .000,00 \times 3 \%=\mathrm{R} \$ 30.000,00$}

Mesmo sendo um tributo de arrecadação nacional, nem toda Pessoa Jurídica ou empresa precisa realizar o pagamento da COFINS. Empresas optantes pelo Simples Nacional, como quem é Microempreendedor Individual ou tem uma microempresa, não precisam recolher o tributo. Isso acontece, pois, essa modalidade de negócios tem seus tributos recolhidos na forma da contribuição mensal ao Simples Nacional, paga no formato de uma única guia mensal, chamada DAS (Documento de arrecadação do Simples Nacional).

\subsection{VANTAGENS DO PLANEJAMENTO TRIBUTÁRIO}

O principal objetivo do planejamento tributário é criar uma estratégia de ações para lidar melhor com as obrigações impostas pelos órgãos de fiscalização, com objetivo de reduzir custos de forma inteligente e legal de acordo com que a legislação, deixando visível qual regime tributário é mais vantajoso e visualizando oportunidades de isenções fiscais ou quais ações são melhores.

De acordo com Fabretti (2009, p. 08), o ensinamento realizado preventivamente, isto é, antes da ação do fato administrativo, buscando seus efeitos jurídicos e econômicos, e as opções legais onerosas, denomina-se Planejamento Tributário. Sendo assim, o planejamento tributário é um modo à disposição para as firmas que buscam diminuir a carga fiscal de maneira lícita. A forma legal tem o nome de elisão fiscal e a maneira ilegal denomina-se evasão ilícita ou sonegação fiscal. Trata-se, consequentemente, do estudo prévio à solidificação dos fatos administrativos e dos efeitos jurídicos e econômicos de uma determinada decisão gerencial, com a meta de achar a alternativa legal menos onerosa para o contribuinte.

Nesse contexto, para Borges (2002, p. 152), este é

RC: 100779

Disponível em: https://www.nucleodoconhecimento.com.br/contabilidade/lucropresumido 
[...] uma técnica gerencial que visa projetar as operações industriais, os negócios mercantis e as prestações de serviços, visando conhecer as obrigações e os encargos tributários inseridos em cada uma das respectivas alternativas legais pertinentes para, mediante meios e instrumentos legítimos, adotar aquela que possibilita a anulação, redução ou adiamento do ônus fiscal.

\subsubsection{RETORNO FINANCEIRO}

Após a apresentação dos cálculos, bem como das bases de cálculos necessárias para obter os valores dos impostos em cada regime tributário supracitado, faz-se necessário uma projeção dos valores que serão obtidos pela empresa ao longo do exercício, para que então seja realizado um planejamento tributário com maior precisão.

Tomando como base a tabela a seguir, pode-se ter uma noção de faturamento ao longo do ano:

Tabela 5 - Faturamento Anual

\begin{tabular}{|l|l|}
\hline Mês & Faturamento \\
\hline Janeiro & $\mathrm{R} \$ 146.309,84$ \\
\hline Fevereiro & $\mathrm{R} \$ 78.849,30$ \\
\hline Março & $\mathrm{R} \$ 83.325,70$ \\
\hline Abril & $\mathrm{R} \$ 82.585,84$ \\
\hline Maio & $\mathrm{R} \$ 72.904,37$ \\
\hline Junho & $\mathrm{R} \$ 61.975,40$ \\
\hline Julho & $\mathrm{R} \$ 67.608,90$ \\
\hline Agosto & $\mathrm{R} \$ 80.315,80$ \\
\hline Setembro & $\mathrm{R} \$ 115.297,00$ \\
\hline Outubro & $\mathrm{R} \$ 60.850,50$ \\
\hline Novembro & $\mathrm{R} \$ 115.839,03$ \\
\hline Dezembro & $\mathrm{R} \$ 51.179,00$ \\
\hline TOTAL & $\mathrm{R} \$ \mathbf{1 . 0 1 7 . 0 4 0 , 6 8}$ \\
\hline
\end{tabular}

RC: 100779

Disponível em: https://www.nucleodoconhecimento.com.br/contabilidade/lucropresumido 
Fonte: Própria.

Vejamos agora, após a aplicação de todos os tributos, qual regime tributário atende melhor as capacidades de rendimento da empresa:

Tabela 6 - Comparativo Tributário entre os Regimes

\begin{tabular}{|l|l|l|}
\hline Mês & Simples Nacional & Lucro Presumido \\
\hline Janeiro & $\mathrm{R} \$ 5.852,39$ & $\mathrm{R} \$ 13.176,94$ \\
\hline Fevereiro & $\mathrm{R} \$ 4.313,06$ & $\mathrm{R} \$ 12.814,13$ \\
\hline Março & $\mathrm{R} \$ 4.557,92$ & $\mathrm{R} \$ 15.846,62$ \\
\hline Abril & $\mathrm{R} \$ 5.648,87$ & $\mathrm{R} \$ 14.334,85$ \\
\hline Maio & $\mathrm{R} \$ 4.986,66$ & $\mathrm{R} \$ 9.162,84$ \\
\hline Junho & $\mathrm{R} \$ 4.239,12$ & $\mathrm{R} \$ 13.274,60$ \\
\hline Julho & $\mathrm{R} \$ 5.097,71$ & $\mathrm{R} \$ 9.690,68$ \\
\hline Agosto & $\mathrm{R} \$ 6.055,81$ & $\mathrm{R} \$ 11.227,47$ \\
\hline Setembro & $\mathrm{R} \$ 8.693,39$ & $\mathrm{R} \$ 30.789,83$ \\
\hline Outubro & $\mathrm{R} \$ 4.624,64$ & $\mathrm{R} \$ 6.358,84$ \\
\hline Novembro & $\mathrm{R} \$ 9.591,47$ & $\mathrm{R} \$ 18.107,88$ \\
\hline Dezembro & $\mathrm{R} \$ 4.237,62$ & $\mathrm{R} \$ 16.036,44$ \\
\hline TOTAL & $\mathrm{R} \$ \mathbf{6 7 . 8 9 8 , 6 6}$ & $\mathbf{R} \$ \mathbf{1 7 0 . 7 3 1 , 1 2}$ \\
\hline
\end{tabular}

Fonte: Própria

Lembrando que a tabela acima compreende todos os tributos do Lucro Presumido somados em 01.

Portanto, com base no faturamento, o Simples Nacional seria o regime tributário que melhor corresponde às especificações da empresa, elevando sua lucratividade e garantindo que a empresa tenha disponibilidade para cumprir com suas obrigações fiscais. 


\section{MATERIAIS E MÉTODOS}

De acordo com Severino (2013, p. 101), a metodologia se constitui aplicando técnicas, seguindo um método e apoiando-se em fundamentos epistemológicos. Tem-se assim elementos gerais que são comuns a todos os processos de conhecimento que se pretende realizar, marcando toda atividade de pesquisa.

"Toda pesquisa deve ter um claro objetivo determinado para saber o que se vai procurar, e o que se pretende alcançar." (IMAÑA-ENCINAS et al., 2019, p. 8)

A metodologia tem por finalidade detalhar os procedimentos e técnicas que foram utilizadas para alcançar os objetivos do trabalho, com clareza e bom desenvolvimento para que assim, toda e qualquer pessoa que ler tenha o entendimento de como foi realizada tal pesquisa.

\subsection{PROCEDIMENTOS METODOLÓGICOS}

Diante do exposto, utilizamos uma abordagem qualitativa, buscando em suas características o entendimento necessário para concretizar os objetivos do projeto científico. Os procedimentos metodológicos representam a escolha do método e a forma de pesquisa a ser utilizada. Este projeto realizou-se por meio de pesquisa bibliográfica, tendo como objetivo principal realizar um planejamento tributário, detalhando cada regime e identificando o melhor, que irá contribuir para a redução de tributação no meio empresarial.

\subsubsection{QUANTO À NATUREZA}

De acordo com Gerhardt e Silveira (2009, p. 35) "este tipo de pesquisa tem como objetivo gerar conhecimentos para aplicação prática, dirigidos à solução de problemas específicos".

"A pesquisa qualitativa pode ser definida como a que se fundamenta principalmente em análises qualitativas, caracterizando-se, em princípio, pela não utilização de

RC: 100779

Disponível em: https://www.nucleodoconhecimento.com.br/contabilidade/lucropresumido 
instrumental estatístico na análise dos dados" (VIEIRA e ZOUAIN, 2006; BARDIN, 2011).

A Natureza classifica-se como pesquisa aplicada, tendo como abordagem qualitativa, visando coletar dados e informações, uma vez que em suas características trazem o entendimento necessário para concretizar os objetivos da pesquisa.

\subsubsection{QUANTO AOS FINS}

Este tipo de pesquisa preocupa-se em identificar os fatores que determinam ou que contribuem para a ocorrência dos fenômenos (GIL, 2007). Para Lakatos e Marconi (2001), este tipo de pesquisa visa estabelecer relações de causa-efeito por meio da manipulação direta das variáveis relativas ao objeto de estudo, buscando identificar as causas do fenômeno.

Quanto aos fins, a pesquisa foi bibliográfica, ressaltando em detalhes os objetos pesquisados, visando um melhor entendimento de seus fatores e facilitando na escolha, bem como a exemplificação com dados para que se tenha noção de que a aplicação incorreta pode ocasionar em perdas.

\subsubsection{QUANTO AOS MEIOS}

A pesquisa bibliográfica é habilidade fundamental nos cursos de graduação, uma vez que constitui o primeiro passo para todas as atividades acadêmicas (ANDRADE, 2010).

Qualquer trabalho científico inicia-se com uma pesquisa bibliográfica, que permite ao pesquisador conhecer o que já se estudou sobre o assunto (FONSECA, 2002).

Quanto aos meios, o projeto estruturou-se em uma pesquisa bibliográfica, onde retoma-se os primórdios do conhecimento, buscando no conteúdo já disponível, por meios de outros autores que dominam o assunto, decompor os conceitos 
apresentados, a fim de diminuir a dificuldade para aqueles que consultam e facilitar na tomada de decisões.

\section{CONSIDERAÇÕES FINAIS}

Este projeto teve como objetivo realizar uma análise comparativa das modalidades de tributação, sendo eles: o Simples Nacional e o Lucro Presumido. A partir de suas devidas Leis, objetivou-se diminuir os custos das empresas com a carga tributária com o intuito de melhor expor as vantagens ou desvantagens da nova sistemática em questão.

O trabalho procurou demonstrar para o empresário a importância de se realizar um planejamento tributário eficiente, para manter sua empresa competitiva e lucrativa no mercado.

O principal destaque do trabalho foi responder à questão que auxiliou na pesquisa: qual a importância de um planejamento tributário pelas empresas, independente do porte, ramo de atividade ou forma de tributação? Onde constatou-se que: o planejamento tributário auxilia na prevenção de erros contábeis e evita possíveis sanções por parte do fisco se o contribuinte deixar de pagar os impostos e tributos, mas o principal objetivo é reduzir a carga tributária e melhorar a saúde financeira das empresas.

Desta forma, esse projeto buscou dar ênfase no planejamento tributário, bem como dois dos regimes tributários mais relevantes, que abrangem a maior parte das empresas de pequeno, médio e grande porte, focando em apresentar os pontos positivos e negativos para então direcionar os empresários ao regime que melhor atende às necessidades da empresa.

Posto isso, conclui-se, através da pesquisa bibliográfica, que o planejamento tributário é a melhor forma de identificar qual é o regime de tributação ideal para a empresa, reduzindo os custos e despesas com a carga tributária. E, por fim, espera- 
se que esta pesquisa possa servir de parâmetro para outros acadêmicos, aos profissionais contábeis e de áreas afins.

\section{REFERÊNCIAS}

ALYRIO, R. D. Métodos e Técnicas de Pesquisa em Administração. Rio de Janeiro: Fundação CECIERJ, 2009.

ANDRADE, A. R. de. Planejamento Estratégico: Formulação, Implantação e Controle. São Paulo: Atlas, 2012.

ANDRADE, E. O. Planejamento Tributário. 2ª̣ edição. São Paulo: Saraiva, 2015.

BALBINOT, M. Planejamento Tributário para um Posto de Combustível. Universidade de Passo Fundo: Passo Fundo, 2014.

BARDIN, L. Análise de conteúdo. São Paulo: Edições 70, 2011.

BARTH, F. L. Planejamento Tributário: Um Estudo de Caso sobre a melhor forma de Tributação entre Lucro Real, Lucro Presumido e Simples Nacional aplicado a uma empresa do ramo Comercial Autopeças situada na cidade de Carazinho RS. Carazinho: Universidade de Passo Fundo, 2014.

BORGES, H. B. Gerência de impostos: IPI, ICMS e ISS. 2ª ed. São Paulo: Saraiva, 2002, p. 152.

BRASIL. Código Tributário Nacional. 2ª Edição. Brasília: DF, 2012. Disponível em: <https://www2.senado.leg.br/bdsf/bitstream/handle/id/496301/000958177.pdf>. Acesso em: 07 de setembro de 2021.

BRASIL. Lei 9.715, de 25 de novembro de 1998. Disponível em: <http://www.planalto.gov.br/ccivil_03/leis//9715.htm>. Acesso em: 08 de setembro de 2021. 
BRASIL. Lei $\mathbf{N}^{\circ} \mathbf{7 6 8 9}$, de 15 de dezembro de 1988. Disponível em: <http://www.planalto.gov.br/ccivil_03/leis/L7689.htm> Acesso em: 11 de setembro de 2021.

BRASIL. Lei $\mathbf{N}^{\circ} \mathbf{8 4 5 1}$, de 23 de dezembro de 1992. Disponível em: <https://www.al.sp.gov.br/norma/14557>. Acesso em: 06 de setembro de 2021.

BRASIL. Lei Complementar № 7, de 7 de setembro de 1970. Disponível em: <https://www.camara.leg.br/proposicoesWeb/prop_mostrarintegra;jsessionid=5 8FF44B2919C40BCC5E5C502FB4BF988. node1 ?codteor $=792380 \&$ filename $=$ L egislacaoCitada+-

PL+7681/2010\#: :text=Institui\%20Contribui\%C3\%A7\%C3\%A30\%20para\%20Fi nanciamento\%20da,Art>. Acesso em: 05 de setembro de 2021.

BRASIL. Lei complementar 123 de dezembro de 2006. Disponível em: <http://www.receita.fazenda.gov.br/Legislacao/LeisComplementares/2006/leicp123.h tm>. Acesso em: 10 de setembro d e 2021.

BRASIL. Lei Complementar № 70, de 30 de dezembro de 1991. Disponível em: $<$ http://www.planalto.gov.br/ccivil_03/leis/lcp/lcp70.htm>. Acesso em: 10 de setembro de 2021.

BRASIL. Lei no 9.718, de 27 de novembro de 1998. Disponível em: $<$ http://www.planalto.gov.br/ccivil_03/leis/19718.htm>. Acesso em: 05 de setembro de 2021.

BRASIL. Constituição da república federativa do Brasil. Disponível em: $<$ https://www.senado.leg.br/atividade/const/con1988>. Acesso em: 10 de setembro de 2021.

CREPALDI, S. A. Planejamento Tributário. 1ํㅡㄹ edição. São Paulo: 2012.

FABRETTI, L. C. Contabilidade Tributária. 10. ed. São Paulo: Atlas, 2009. 
FABRETTI, L. C. Contabilidade Tributária. 11. Ed.- 2. Reimpr.: São Paulo: Atlas, 2009.

GERHARDT, T. E.; SILVEIRA, D. T. Métodos de pesquisa. Porto Alegre: Editora da UFRGS, 2009.

GIL, A. C. Como elaborar projetos de pesquisa. 60 Ed. São Paulo: Atlas, 2007.

HIGUCHI, H. Imposto de Renda das Empresas: Interpretação e Prática: Atualizado até 10/01/2014. 39ª ed., São Paulo: IR Publicações, 2014.

IMANA-ENCINAS, J.; OTACILIO, A. S. O trabalho científico na metodologia científica. Brasília: Universidade de Brasília, Departamento Florestal, 2019.

LAKATOS, E. M.; MARCONI, M. de A. Fundamentos de Metodologia Científica. $4^{\text {a }}$ edição. São Paulo: Ed. Atlas, 2001.

NAYLOR, C. M. Fundamentos constitucionais do Simples Nacional, Jus navigandi, ano 13, n 1848, 23 jul. 2008.

OLIVEIRA, G. P. Contabilidade Tributária. 3. ed. São Paulo: Saraiva, 2009.

OLIVEIRA, L. M. de. et al. Manual de Contabilidade Tributária. 12. Ed., São Paulo: Atlas, 2013.

PINTO, J. R. D. PIS/PASEP e COFINS. 2ª ed. Atual. Caxias do Sul: Lorigraf, 2011.

RODRIGUES, A. O. et al. IRPJ e CSLL 2016. São Paulo: IOB Folhamatic, 2016.

SANTIAGO, S. Simples Nacional: O Exemplo do Federalismo Fiscal Brasileiro. São Paulo: Saraiva, 2011.

SEVERINO, A. J. Metodologia do trabalho científico. Livro eletrônico, $1^{\text {a }}$ edição. São Paulo: Cortez, 2013. 
VIEIRA, M. M. F.; ZOUAIN, D. M. Pesquisa qualitativa em administração. 2. ed. Rio de Janeiro: FGV, 2006.

Enviado: Outubro, 2021.

Aprovado: Novembro, 2021. 